NBER WORKING PAFER SERIES

\title{
CONDITIONAL MEAN-VARIANCE EFFICIENCY \\ OF THE U.S. STOCK MARKET
}

\author{
Charles Engel \\ Jeffrey A. Franke1 \\ Kenneth A. Froot \\ Anthony Rodrigues
}

Working Paper No, 2890
NATIONAL BUREAU OF ECONOMIC RESEARCH
1050 Massachusetts Avenue
Cambridge, MA 02138
March 1989

\begin{abstract}
We thank the Alfred P. Sloan Foundation and the 01in Foundation for generous research support. All errors are our own. This paper is part of NBER's research program in Financial Markets and Monetary Economics. The views expressed here are those of the authors and do not necessarily reflect those of the Federal Reserve Bank of New York, the Federal Reserve System, or the National Bureau of Economic Research.
\end{abstract}


NBER Working Paper \#2890

March 1989

\title{
CONDITIONAL MEAN-VARIANGE EFFICIENCY
}

OF THE U.S. STOCK MARKET

\begin{abstract}
We apply the method of constrained asset share estimation (CASE) to test the mean-variance efficiency (MVE) of the stock market. This method allows conditional expected returns to vary in unrestricted ways, given investor preferences. We also allow conditional varlances to follow an ARCH process, The data estimate reasonably the coefflcient of relative risk aversion, though are unable to reject investor risk neutrailty. We reject the restrictions itsplied by MVE, although changing conditional varlances improve statistically upon measured market efficiency. We find that unrestricted asset-share and ARCH models help forecast excess returns. Once MVE is imposed, however, this forecasting ability disappears.

Charles Enge1

Department of Economics

University of Virginia

Charlottesville, va 22901

Kenneth A. Froot

Department of Economics

Massachusetts Institute of Technology

Cambridge, MA 02139

Jeffrey A, Frankel

Department of Economics

Harvard University

Cambridge, MA. 02138

Anthony Rodrigues

Federal Reserve Bank of New York

Federal Reserve P.O. Station

New York, NY 10045
\end{abstract}




\title{
Conditional Mean-Variance Efficiency \\ of the U.S. Stock Market
}

\author{
Charles Engel \\ University of Virginis and NBER
}

Jeffrey A. Frankel

Harvard University and NBER

\author{
Kenneth A. Froot \\ MIT and NBER
}

\section{Anthony Rodrigues}

Fedetal Reserve Bank of New York

This paper uses a technique that we call Constrained Asaet Share Estimation (CASE) to test the conditional mean-variance efficiency (MVE) of the U.S. atock market. The technique is useful in time-series testa of aimple asset pricing models because it allows estimated expected returns to vary in an unrestricted way. It was first applied in a macroeconomic context in which the "market" portfolio included not only equities, but also money, bondo and real estate. ${ }^{I}$ It has since been applied more widely to other portfolios and has been extended to allow for variation in conditional second as well as first moments, as in an autoregressive-conditional-heteroskedasticity (ARCH) model..$^{2}$

There is still a need for a clear statement of the advantages of the CASE method over earlier tests of the MVE hypothesis for the stock market. Briefly, these advantages are of three sorts. First, the technique does not impose the condition that expected returns are constant over time, or even that they change in a Blowly moving way. Rather it allows expected returns to vary freely, as they must, for example, whenever new information which may not be observed by the econometrician becomes available to the investor. ${ }^{3}$ In addition, in some of the tests below we allow

\footnotetext{
ISee Frentel [1882, 1985a), Frankel and Dicken (1984), Fronkel and Engel (1094), and Wille (1982).

${ }^{2}$ Feron, Kandal and Stambaugh (1987) and Rayner (1986) teat the eonotent-veriance vertion on atock portfoliow. Bodurtha

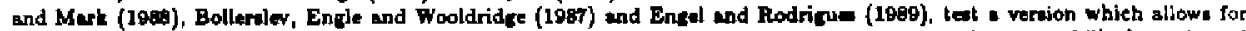
chanpint conditiond ewond moment on portfolion, respectively, of atoels, domeatic bondu, end abort-torm bilis denominated in different currencies.

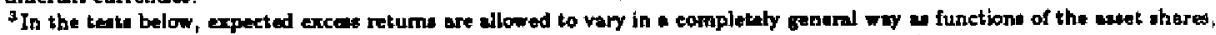
requiring only that a ef of preference parameters consintent with the Here dous of utifity function remain conatant.
} 
second moments to vary sccording to an ARCH process." Allowing for such variation in eonditional moments is essential for a properly specified test of MVE. lo fact, there is considerable evidence that both the conditional expectation and conditional variance of excess returng contain important predictable components.

The second advantage of this method is that, by allowing the CAPM betas to evolve along with the characteristics of the underlying assets, longer time series can be used to teat MVE. In the past, tests of unconditional MVE coped with changing conditional moments by using short test periods, usually 5 years or less. There are two problems with this procedure. First, there appears to be a substantial amount of conditional variation in both firat and second moments over forecast horizons of much less than 5 years. Second, while limiting time-series samples to 5 years makes the assumption of constant conditional moments more believable, it also reduces the power of tests of MVE. Low power can potentially explain the lack of any measured relationship between risk and return in tests of MVE. ${ }^{7}$ The use of longer time series also reduces the need to develop small-sample test statistics, such as that suggested by Shanken (1987). With large time-series samples, the distributions of conventional test statistics are likely to be closer to their asymptotic approximations.

The third advantage implicit in the CASE method is that-it nests MVE in a more general, but economically meaningful, theory of portfolio determination. In contrast, most tests of the null hypothesis of MVE have no clear alternative hypothesis. This feature ia particularly important because many teats do in fact reject MVE; when one rejects the null hypothesis it is crucial to have some idea of what the altermative is. In some of the tests below, the alternative to MVE is that investors' portfolio shares are linearly related to expected returns, and possibly to conditional variances as well, but that investors do not compute covariances with the market portfolio in the

\footnotetext{
t The ARCH process doea not allow necond moments to vary freeb however. It il analogous to eatimating the flrat moments by an ARDMA procese, in which this period's expectation is related to recent resliestiona, rather than by the CASE technique, in. which expectations ean racy freely.

${ }^{3}$ See, for exampie, Fama snd French (1988) and Poterba and Summers (1987) for evidence on the predictability of atock market returns, and Bolleriev (1985) and Bolleralev, Engle and Wooldridge (1988) for evidence on the predictability of conditional variarken of exceen returns. Theae findinge couplat with the resulth o[ Hansen and Richard (1987), who ohow that the conditionaly and unconditionally mean-variance eficient frontien are generally different, sugget that such variation is conditionai moments is importanl for test of MVE.

Fams and French (1988) document aubetantis! mean revenion at forecant horisone of $3-5$ yeara. Pindyck (1984) snd Poterba end Summen (1986) find evidence of high-frequency variation th conditiond ctock-market veriances.

${ }^{7}$ See, for example, Sshwert (1983), Gibbon, Rose and Shanken (1986), MacKinlay (1987), and Gibbons and Shanken (1987)
} 
precise way that MVE would imply they should.

Our tests below emphasize the nested nature of the hypotheses we consider. We pay special attention to the importance of ARCH vo. MVE va. the asset shares themseives in explaining risk premis. The broad findings can be summarized as follows. First, we find that stock-market shares by themselves have statiatically significant explanatory power in predicting monthly excess stock returns. This is what we would expect if the stock market is mean-variance efficient and if required returns change over time. However, we reject the restrictions implied by constant-variance MVE. Moreover, the ability of asset shares to forecast future excess returns disappears once the MVE restrictions are imposed. Something very different than MVE appears to be responsible for asset shares' ability to predict atock returns. Indeed, for a majority of the portfolios we construct, higher conditionally expected returns are agsociated with lower value shares.

One might conjecture that MVE holds and that these results are an artifact of the maintained assumption that conditional variances are constant. Indeed, we find that the data reject the hypothesis that the market is mean-variance efficient with a constant variance against the alternative that the market is mean-variance efficient with a conditional covariance matrix that evolves according to an ARCH process. Time-varying second moments therefore move the mean-variance efficient frontier closer to the market portfolio. This is good newa for ARCH, but not for MVE: we cannot reject the hypothesis that the ARCH-MVE model can explain no portion of excess returns. Nevertheless, the data produce a sensible estimate of the coefficjent of relative risk aversion of 2 , with a standard error of about 1.5, so that, while we cannot reject the hypothesis that investors are risk neutral, we can reject hypotheses that they are strongly risk loving or risk averse.

Finally, we test a generalized ARCH specification, which does not impose MVE, against the null hypothesis that the market is conditionally mean-variance efficient and that conditional variances evolve according to an ARCH process. Once again we reject the restrictions imposed by by conditional MVE.

The paper is structured as follows. Sections 1 and 2 briefly describe the model and the data, respectively. Section 3 tests for constant-variance MVE. We introduce our ARCH specification in gection 4, and test an unrestricted model as well as an ARCH-MVE system. Section 5 summarizes

\footnotetext{
- One posaibility is that the managers of ponsion funde and the atber funda thak hold most equitia are concerned only with minimising the veriance of their own performance, rather than computing covariences with the aggregate portfolion beld by individablo they in theory ohould.
} 
our general nesting procedure for the hypotheses of interest and offers our conclusions.

\section{The model}

Mean-variance efficiency implies that the vector of conditional risk premia is a linear combination of the asset shares in the portfolio, with the weights proportional to the conditional variance of asset returns:

$$
E_{t}\left(\mathbf{r}_{t+1}\right)=p_{t} \boldsymbol{\Omega}_{t} \lambda_{t}
$$

where $E_{t}\left(r_{t+1}\right)$ is the expected excess return above the riskless rate on an $N \times 1$ vector of assets conditional on all information available at time $t, \Omega_{t}$ is the conditional variance of returns between $t$ and $t+1, \lambda_{i}$ is the $N \times 1$ vector of portfolio weights, with $\sum_{i=1}^{N} \lambda_{t, i}=1$, and $\rho_{t}$ is a preference parameter - the coeficient of relative rigk aversion. If the aggregate stock portfolio is the "market" portfolio, MVE is equivalent to the CAPM. To see this, note that the right-hand side of (1) is equivalent to the risk-adjusted conditional expected return on the aggregate (or market) portfolio

$$
E_{k}\left(r_{t+1}\right)=\beta_{t} E_{t}\left(m_{t+1}\right)=\beta_{t} \lambda_{t}^{\prime} E_{t}\left(r_{t+1}\right)
$$

where

$$
\beta_{i}=\frac{\Omega_{t} \lambda_{t}}{\lambda_{t}^{\prime} \Omega_{t} \lambda_{t}}=\frac{\operatorname{cov}\left(m_{t+1}, r_{t+1}\right)}{\operatorname{var}\left(m_{t+1}\right)} .
$$

This expression makes it clear that the vector of sub-portfolio $\theta_{1}$ s varies both with the shares 0 assets in the portfolio, $\lambda_{t}$, and the conditional covariance matrix, $\Omega_{t}$, and thus may move substan tially over short time intervals. Also, note that given preferences and $\Omega_{1},(1)$ is a complete model o expected excess returns: MVE implies that asset shares are sufficient statistics for optimal forecast of excess returns.

Under rational expectations, we can replace the vector of expected excess returns with th actual returns by including a prediction error that is orthogonal to all information at time $t$ :

$$
\tau_{t+1}=\rho_{l} \Pi_{l} \lambda_{t}+\epsilon_{1+1}
$$

where $\epsilon_{t+1}=r_{i+1}-E_{i}\left(r_{t+1}\right)$. The insight in Frankel (1982) was that information about t conditional covariance matrix of returns can be obtained from the error terms, since under MVI

$$
\Omega_{\mathrm{f}}=E_{t}\left(\epsilon_{t+1} \epsilon_{t+1}^{\prime}\right)
$$


MVE therefore imposes a set of restrictions thet are highly nodinear in that they constitute proportionality between the coefficient matrix and the variance-covariance matrix of the error term in (2).

To evaluate (3), we mugt take s position on whether $\Pi_{t}$ is congtant over time, In sections 3 and 4 below, we asgume that $\Pi_{t}$ is constant and that it follows an ARCH process, respectively. We test the hypotheses that MVE holds against more general alternatives in which investors forecast excess returns as a function of asset ahares and past prediction errors. The exact specifications for the alternative hypotheses are discumed in sections 3 and 4 . We also test the MVE hypotheses above, as well as the more general alternatives, against an even more restrictive null hypothesis: that investors expect conditional excess returas to be zero. The results of these tests are also discussed in gections 3 and 4 . Section 5 presenta a diagram which makes it easy to see the regults of our neated hypothesis tests.

\section{The data}

Our tests use monthly stock returas from the New York and American Stock Exchanges from January 1955 to December 1984. Becaube of the computational dificulties in estimating (2) we were forced to reduce the size of the cross section. ${ }^{9}$ In the testa below we aggregate atocks into $N=11$ (and sometimes 7) industry portfolios.

Table 1 describes the aggregation of atocks into indugtry portfolioe. The returns for each portfolio are value-weighted average returns. The $N \times 1$ vector of portfolio shares, $\lambda_{1}$, is the value of the stocks in the portfolios as a fraction of the total value of all stocks. Because it is desirable to group together equities that have highly correlated returns, we tried to put similar industries into the same portfolio. ${ }^{10}$ Stambaugh (1982) aggregates into 20 industries, roughly by type of final output. We further aggregate into 11 industries, combining some of Stambaugh's catagories. Table 1 shows Stambaugh's 20 industries, as well as the 11-industry aggregation that we use to perform our maximum likelihood tests of MVE. Table 1 also reports a 7 -indugtry aggregation that we use for the ARCH estimation in section 4 .

\footnotetext{
If there are $N$ anets, the computation involves a parameter matrix of dimention $N(N-1) / 2 \times N(N-1) / 2$ that must be repeatedy inverted. Engel and Rodriguw (1988) offer a Wald teat verion of the CASE teat that gets around thid problem, and slow one to consider larger vectore of encets. We apply it in Section 3 below.

1" On the othe hand, we would not want to includt together the mupplien of intermediate products and the producers of finsl output in the same induntry. When ateel prices riet, the cont of producing suto inereases so that it is possible that steel producers' profiva ribe when suto manufacturen profits decline.
} 
The value shares, $\lambda_{t}$, are used to predict excess returns between time $t$ and $t+1$. The share are measured monthly from the last day of January 1955 to the lagt day of November 1984 (35 observations), while the returns are calculated as the dividend plus appreciation over the previou month beginning the last day of February 1955 and ending the Iast day of December 1984 . A returns are nominal excess returns above the return on one-month Treasury bills recorded b Ibbotson Associates (1986).

\section{Tests of MVE with constant conditional variances.}

If relative risk aversion and the return covariance matrix are constant, $\rho_{t} \Omega_{t}=\rho \Omega$, we ca write demands for assets as a function of their own rate of return and returns on all other equitie We would have,

$$
\lambda_{t}=\mathbf{B} E_{t}\left(r_{t+1}\right)
$$

where $\mathrm{B}$ is an $N \times N$ matrix of coefficients. By inverting the system of equations in (4), we obta a measure of expected excess returns,

$$
E_{l}\left(\mathbf{r}_{t+1}\right)=\mathbf{A} \lambda_{1}
$$

where $\mathbf{A}=\mathbf{B}^{-1}$. This gystem of equations is a generalization of a static model of MVE. MV imposes the restriction that the matrix of coefficients $\boldsymbol{A}$ be proportional to the variance of forecast error, $\epsilon_{t+1}$. Using ex post returns, (5) can be written:

$$
r_{t+1}=A \lambda_{t}+\epsilon_{t+1}
$$

Although the values of the equities are endogenous variables in an economic sense, they are $\mathbf{s}$ uncorrelated with the prediction errors, which under rational expectations are uncorrelated w all information available at time $t$. (Under the null hypothesis that MVE holds precisely, predict errors are the only source of errors that enter the equation. ${ }^{11}$ ) Thus the system in (6) can estimated consistently using ordinary least squares, equation by equation. ${ }^{12}$

Table 2 reports the results from estimating the unconstrained aystem of equations (6). Few the coefficients individually are significantly different from zero. Unsurprisingly, the $R^{2} \mathrm{~s}$ are

\footnotetext{
11 For example, Engel end Rodrigues (1989) show how iid measurement error in the rates of return could be included in regidual, $c_{t+1}$ -

${ }^{19}$ Note that the $N$ aset shared, $\lambda_{1}, \ldots \lambda_{1}, N$, are periectly collinear becaune they oum to 1 . This does not pose a problen the estination of $(7)$, however, becaune the equationa do no: include a conbant term.
} 
very high, and nove exceeds . 10 . We can reject at the 95 percent sysi the hypothesis that the asset abarea bave no explanstory power for excess atock returns. The log-likelihood value for the 11 equation aystem is $\mathbf{8 7 0 9 . 3 5}$. The log-likelihood when all 121 coefficient are constrained to be zero is 8592.57. Twice the difference is distributed as $\chi_{121}^{2}$. The value of the statistic is 233.56 compared with a critical value of $147.399^{1314}$

There is mixed support for one of our ansumptions - that forecasts are rational. This agsumption implies that there is no serial correlation in forecast errors. We performed Breusch-Godfrey tests for serial correlation from orders 1 to 20 . We report the chi-square statistics only for the tests of the existence of $20 \mathrm{th}$ order autoregressive or moving average errors. In only four of the regressions can we reject the null bypothesis of no serial correlation up to 20 th order at the 95 percent level.

Under the MVE hypothesis, this unconstrained system of inverted asset demand equations is not estimated efficiently. If we impose more structure on the gystem we can hope to improve the precision of our paraneter estimates. So we will eatimate the system of equations in (6) imposing the MVE constraints:

$$
r_{t+1}=\rho \Omega \lambda_{t}+\epsilon_{t+1}
$$

so that $A=\rho \Omega$. The $N$ equation system (7) must be estimated by maximum likelihood techniques, imposing an unusual crose-equation restriction - between the matrix of coefficients in the regressions and the variance matrix of the regression errorg. Note that the assumption that $\Omega$ is constant is not the same as the usual assumption in MVE teats of constant betas and expected returns. As we saw in the previous section, even with a constant covariance matrix, the betas, and bence the expected returns on all securities including the aggregate or "market" portfolio, will vary over time in a general, unrestricted way. ${ }^{15}$

Table 3 reports the maximum likelihood results of (7). The log-likelihood yalue is necessarily lower than the log-likelihood for (6) because (7) is a restricted form of (7): 8593.68 (as compared to the unrestricted log-likelihood of 8709.35$)$. We also report a chi-square statistic for the restrictions

\footnotetext{
15 The 99 pereent eritical velue is 169.38 .

14 The only prior belief we have about the coefficientr is that the return on anet $j$ ohould be positively related to the share of aset $j$ in the total portiolio. If we think of the market portolio a comprised only of atocke, then in equilibrium inwentors vill demand a higher retum trom a given atock portfolio the more of it they are required to hald. Tabje 2 shows that in aut

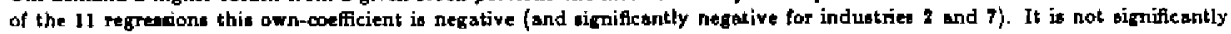
positive in any of the regreanions.

15 Franhel (1985a)
} 
implied by (8). We impose 120 restrictions on the unconstrained system (121 coefficients are constrained to be proportional to their corresponding elements in the variance matrix). The test otatiatic is distributed $\chi_{120}^{2}$, and its value is 231.34 . We can easily reject the hypothesis of MVE at the 99 percent level. Comparing the reaults from table 3 to table 2 , it is easy to see the source of the rejection. When the coefficients are constrained, they are much smaller than when they are unconstrained. Under the MVE constraints, an incresse in the share of an asset has a much smaller impact on risk premia.

If one were willing to accept the MVE estimates on the basis of prior beliefs, they yield in some ways much more plausible aseet pricing equations. We noted that in the unconstrained regressions we frequently found that an increase in an asset share would actually decrease that asset's expected return. That is not possible with the constrained MVE estimates.

Also, the point estimate of the coefficient of relative risk aversion, $p$, is very plausible -2.03 . It is very close to the "Samuelson presumption" of a likely value for average risk aversion. The coefficient is not estimated precisely, however, as it is not statistically different from zero at the 95 percent level. But its 95 percent confidence interval ranges only up to about $5.3-8$ till a believable estimate for average risk avergion.

On the other hand, the constrained model does a yery poor job of predicting excess returns. The failure to reject the hypathesis that $\rho=0$ implies that asset shares provide no statistically significant explanatory power for risk premia under the MVE restrictions, because the coeficients on the shares are all multiples of $\rho$. Above we mentioned that the log-likelihood when the coefficients are all constrained to be zero is 8592.57 . The likelihood under the MVE restrictions is only 8593.68 - a meager increase of 1.11. MVE vitiates the predictive power of the asset shares alone.

The estimates reported in Tables 2 and 3 calculate the shares as a fraction of total equity inveatment. If, however, there are positive net holdings of the riskless asset, then the shares should properly be calculated as a Iraction of total equity investment plus the total net value of the riskless asset. The riskless asset could have a positive net value if the government issues riskless short-term bonds, and investors consider government bonds to be additions to net wealth (so that they do no fully discount future tax liabilities) or if the government issues money. We estimated the mode under the assumption that the relevant measure of the net supply is the vajue of all goveramen 
bonds (which are calculated by Cox, 1985), and again under the susumption that the value of outstanding Treasury billa messure the net supply of the riskless asset. In both cases, there was almost no change in the estimateg.

We considered two other formulations for the coefficient of relative risk aversion, besides assuming that it is constant. In the firat, we assumed constant absolute risk averaion. In that case, $p_{l}=b W_{t}$ where $b$ is the coefficient of absolute risk averaion and $W_{t}$ is the value of all equitiea at time $t$. In the second, we considered a more general formulation consistent with the Hara class of utility functions, $\rho_{l}=a+b W_{t}$. If $b=0$ we have the constant relative risk averaion case, and if $a=0$ we have congtant absolute risk avergion. Again, however, these versions of the model failed to improve the constrained model's performance. ${ }^{16}$

\subsection{A wald teat of MVE with congtant conditional variances.}

Maximum likelihood estimation of MVE is a difficult task. The constraints between the coefGients and the variance cause grave problems in finding the maximum of the likelibood function. The estimation is expensive and time consuming. The entire aystem must be estimated simultaneously, which in the case of the 11-agset system means simultaneously estimating 122 coefficients. The complexity of the problem increases with the square of the number of equations and assets. If we were to estimate the model even for all 20 of Stambaugh's original portfolios, it would mean maximizing a very messy function over 401 parameters.

If we are interested in testing MVE, but not in actually obtaining the constrained coefficient estimates, we do not need to estimate the constrained set of equations. A Wald test can be performed using only the unrestricted model. In this case, the unconstrajned model (6) is particularly easy to estimate, because it requires only equation-by-equation ordinary least squares. Engel and Rodrigues (1988) provide an expression for the Wald statistic for the MVE restrictions.

The Wald statistic is not difficult to compute even for large collections of aasets. We can test the MVE restrictions for the entire eet of 20 industry portfolios composed by Stambaugh. We again reject the MVE restrictions easily. The test statistic is distributed $\chi_{19}^{2}$, and has a value of 58.99 , well above the 99 percent level. ${ }^{17}$

\footnotetext{
1EIn order to save opace, wa do not report these resulta.

17 The comparable Wald teat for the 11 -anet aggregation yield a tratiotic ditributed as $x_{10}^{2}$ equal to 22.76 . This also rejects the MVE retrictions at the 99 perent leval. These particular teato teatrict only the diagonaj elemente of the returT covariance matrix, and yet they reject easily.
} 
The estimates of this aection provide little support for MVE of the stock market. In all of the testa performed, the restrictions that MVE places on a more general asset demand model are strongly rejected.

\section{Teste of MVE with ARCH conditional variances.}

In the estimates reported in section 3 , we assumed that return covariance matrix, $\Omega_{t}$, was constant over time. Becauge it has become clear in recent years that conditional variances show a considerable amount of variation, we turn to a model of time-varying conditional variances.

In simple regression models, the presence of heteroskedasticity often does not affect the consiatency of the coefficient estimates, although it does cause standard calculations of test statistics to be inconsistent. When the MVE restrictions are imposed, however, changes in variances imply changes in coefficient estimatea, which in turn imply changes in expected excess returns. The coefficient on the asset shares in the constrained model must move over time if $\Omega_{t}$ does, so holding $\Omega_{t}$ constant leads to inconsistent caefficient estimates.

Inspection of (2) makes it easy to see why it is important to allow for variation in $n_{t}$. There are two possible sources of variation in expected returng if the measure of relative risk aversion is constant: changes in asset shares, $\lambda_{t}$, and changes in $\Pi_{1}$. Suppose, for example, that favorable news about a atock is snnounced. One could casily think of cages in which the price is pushed up, increasing the stock's share in the aggregate portfolio, even though its expected return is now lower with the news. If the market is mean-variance efficient, this can happen when the riskiness of the asset declines - its own variance falls, or its variance with other assets declines. But, for the $j$ th asset, this is exactly a change in the $j$ th row of $\Omega_{t}$.

The burgeoning econometric literature that proposes general corrections for heteroskedasticity is not applicable to this model. That literature relies generally on procedurea in which consigtent estimates of the residuals are obtained before any heteroskedasticity correction is made, and those estimated residuals are used to construct heteroskedasticity-consiatent statistics. In our MVE tests we must correct for time-varying variances when we estimate the regression coefficients because the coefficients move with the variance. In order to do this, we need an explicit model of the variance process.

Of course, our model is partial equilibrium in the sense that it does not indicate the nature o 
the exogenows variables that determine asset prices. It takes the stochastic processes of returns ss given, and computes the mean-variance efficient portfolio from these. In particular, it gives us no indication of how variances should change over time.

We choose to model variances empirically following Engle's (1982) ARCH process. The ARCH take the conditional variance of this period's forecast error to be a function of past forecast errors. It is not based on any theoretical notion of how the general equilibrium of the oconomy works. It is an ad hoc model that seems to work well in practice.

The univariate representation of a first-order ARCH would be $\sigma_{i, i}^{2}=\alpha+\gamma \epsilon_{i, i}^{2}$. The variance of the forecast error of the ith stock between time $t$ and $t+1$ is given by $\sigma_{t, i}^{2}$, and $\epsilon_{t, i}^{2}$ is the square of the forecast error made between time $t-1$ and $t$. This equation states that if we make a large forecast error in one period, the variance of our forecast for the next period will be greater (assuming $\gamma>0$ ).

In this aection, we apply a multi-equation version of $\mathrm{ARCH}$ to the MVE problem. Because of the difficulty in estimating large ARCH syatems, we bave further aggregated the assets into the 7 portfolios described in table 1. Even with only 7 equations to estimate, the dimension of the ARCH problem can be quite large. For example, even if we restrict ourgelves to first-order ARCH in which the variances and covariances this period are related only to the squares and crossproducte of forecast errors from the previous period, the problem is unmanageably large. There are 28 independent elements in the covariance matrix. If each element were linearly related to the 28 lagged squares and crose products of the forecast errors, there would be 812 variables to estimate. More general forms of ARCH would relate the variance to more than one lag of the eross-products of forecast errors, or to lagged variances (ag in Bollerslev's (1986) GARCH).

Given the complexity of estimating the MVE-ARCH system, and given the limited amount of data, it is belpful to lower the number of ARCH coefficients. Our test of MVE uses a parsimonious version of $\mathrm{ARCH}$, in which the model,

$$
E_{t}\left(r_{t+1}\right)=\rho \Omega_{t} \lambda_{t}
$$

has return variance given by:

$$
\Omega_{t}=P^{\prime} P+G \epsilon_{t} \epsilon_{t}^{\prime} G
$$


We treat as parameters the upper triangular matrix $P$, and the diagonal matrix $G$. Under thi formulation, each element of $\Omega_{t}$ is linearly related to its corresponding component in the matri of cross-producte of lagged forecast errors. There are only 35 coefficients to estimate. A furthe advantage of the ARCH in ( 9 ) is that it enforces positive semi-definiteness on the covariance matri $\Omega_{t}$. This turns out to be helpful in estimating the constrained model by maximum likelihood.

The unrestricted form of the inverted aystem of asset demand equations is given by:

$$
E_{t}\left(\mathbf{r}_{t+1}\right)=\mathbf{A}_{t} \lambda_{t}
$$

MVE imposes the restriction that $\boldsymbol{A}_{t}=\rho \Omega_{t}$, where $\Omega_{t}$ is the conditional variance of $r_{t+1}$. practice, if MVE is to be nested in the general system of asset demands, then the elements of $\mathbf{A}_{l}$ the general system might be related to the same variables that $\Omega_{1}$ is assumed to be related to bu in an arbitrary way. More specifically, we assume that in the unrestricted model, the coefficie matrix $\mathbf{A}_{t}$ evolves according to:

$$
A_{i}=Q^{\prime} Q+F \epsilon_{t}^{\prime} \epsilon_{t} F
$$

where $Q$ is upper triangular and $F$ is diagonal, and the conditional covariance matrix of return $\Omega_{t}$, is given by (8). The MVE constraint, that $\Lambda_{t}=\rho \Omega_{1}$, imposes 34 additional constraints on $t$ unconstrained asset demand equations in (9).

For our restricted ARCH-MVE model in ( 8 ), the log-likelihood for observation $t$ is given by

$$
\mathcal{L}=-(7 / 2) \ln (2 \pi)-(1 / 2)\left|\Omega_{t}\right|-(1 / 2)\left(r_{t+1}-\rho \Omega_{t} \lambda_{t}\right)^{\prime} \Omega_{t}^{-1}\left(r_{t+1}-\rho \Omega_{t} \lambda_{t}\right)
$$

where $\Pi_{t}$ is defined in $(8)$, and $\epsilon_{t}=r_{t}-\rho \Omega_{t-1} \lambda_{t-1}$. Maximization of (11) is diffcult for sevel reasons. First is the constraint between coefficients and variances. Second is the recursive nat of the problem (so that the likelihood at $t$, defined above, depends on all observations from 1 to Third is the large number of parameters to estimate simultaneously. We estimated the system a modifed version of a maximum likelihood program available in the Gauss programming packa It uses a technique based on the Berndt, Hall, Hall and Hausman (1974) algorithm.

Before turning to the results of the ARCH estimation, it is ugeful first to examine the c strained MVE estimates on the 7 equation system when $\Omega_{t}$ is constrained to be constant, as in previous section. Table 4 shows that the 7 -equation system performs much like its 11-equation co terpart. The estimate of the relative risk aversion parameter is close to 2.0 . However, it is still 
statistically different from zero, which indicates that the aseet share dats with the MVE constrai: imposed do a poor job of explaining expected returns. The log-likelihood with MVE imposed 5558.56. This compares to a log-likelihood of 5603.56 for the corresponding constant-coefficie unconstrained system of asset demand equations. In this case, MVE imposes 27 constraints on 1 general system. The tegt statistic is distributed $\chi_{27}^{2}$, with a size of 70.00 . The MVE constrai can be rejected strongly at the 99 percent level.

Table 5 reports the results of the MVE restrictions imposed on the ARCH systern. There two hypotheses to test here. The first asks whether we can reject the constant-variance MVE mo in favor of the ARCH-MVE. A rejection would imply that time-varying variancea atatistically red: the distance between the stock-market portfolio and the mean-variance efficient frontier. Suc rejection would lead us to the other intereating hypothesis: can we reject the restrictions impl by MVE on the unrestrieted ARCH system in (9) and (10)? This would involve a test of hypothesis that $Q=P$ and $F=G$.

The log-likelihood for the ARCH-MVE model in (9) is 5573.97. The constant variance vere of MVE is a special case of this ARCH model, in which the $G$ matrix from (9) is constrained te zero. This imposes 7 constraints on the ARCH system. Our test statistic is 30.82 and is distribu $x_{7}^{2}$ : we reject the constant-variance restrictions at the 99 percent level. ARCH therefore impro significantly on the constant-variance form of MVE.

Four of the 7 ARCH coefficients (elements of the $G$ matrix) are significantly different $f$ ) zerc at the 95 percent level. These coefficients are all quite small in magnitude. The squar each element gives the coefficient relating the variance in each equation to itg own lagged squa forecast error. Only one of the squared components of $G$ is greater than 10 .

The point estimate of $\rho$ is 1.91 - again close to the Samuelson value of 2.0 . Once again, estimate is not statistically different from zero at the 95 percent level (although it is now signifi at the 80 percent level). The most important question is whether the ARCH-MVE model is restrictive relative to the general ARCH system given in (9) and (10). This system will pror a log-likelihood value at least as large as the value we reported above - 5603.56 - for the ver of the unconstrained model in which $\boldsymbol{A}_{\boldsymbol{t}}$ is constant. But even if its likelihood was no larger this, the size of the test statistic (distributed $\chi_{34}^{2}$ ) for testing the MVE constraints on the A] 
model would be 59.18. MVE would therefore be rejected at the 99 percent level. So we do not eve: need to stimate the unconatrained asset-pricing equations with $A_{1}$ varying over time to know that MVE is rejected.

We conclude that while letting the variance change over time is important in improving the explanatory power of MVE, it does not improve it enough relative to an unconstrained system of arget-demand equations. 


\section{Summary and Conclusions}

Figure 1 provides a graphical summary of our nested bypothesis teats. At the top of the figure is the most unrestricted model we consider, the unrestricted ARCH model in equations (9) and (10). At the bottom of the figure is the most restrictive model, that anset shares are of no help in explaining required returns, or equivalently, that risk aversion is zero. For each pair of models, the line connecting them reporta the results of a test of whether the lower model (the null hypothesis) can be rejected in favor of the upper model (the alternative hypothesis). It is easy to bee that both of the MVE formulations - the constant-variance cage in equation (7) and the ARCH case in (8) - are rejected when compared with any more general alternative hypothesis. Worse, there is nc evidence in favor of these MVE models even when they are pitted as alternative hypotheses againa' the straw-man model in which asset shares don't matter at all $\left(\mathbf{A}_{i}=0\right.$ in equation (9)).

There are several ways to rationalize these results. One would be that the true asset pricin model is not the CAPM, but rather the APT, a version of the intertemporal CAPM, or even th one-period CAPM plus some other omitted variable. A second explanation for the resulta woul rely on the Roll (1977) critique. If the stock market is very unlike the true "market" portfolio, w would not expect to find MVF, even if the CAPM holds. ${ }^{18}$

Indeed, under this explanation, the aspet shares and ARCH processes cannot be accuratel observed. A third explanation of the resulta would be that the reaiduals in (2) lead to poor measure of the conditional variances. If "peso problems" affect atock market returns, the estimated reaiduai will be biased. Imposing the MVE restrictions only compounds the problems. For example, it ! well known that in the five years following the atock-market boom of August 1982, the market ros at an average annual rate of 22 percent. Few would argue in retrospect that it is possible to obtaj from this period ex post, valid messures of ex ante expected risk and return. Thus if the mod, in (8) were true we would expect that unconstrained asget shares and ARCH would predict exce: returns, but this could be erased by imposing the MVE restrictions which are-not exactly aatisfif in our sample.

\footnotetext{
15 Similar results were found, hovever, when monoy, bond, and real ablate werc allowed into the portfolio (Frankel, $1985 x$ and Franltal and Dickens, 1984) and when foreigl aesete were allowed (Frankel, 1082, and Frankel und Engel, 1984).
} 


\section{Reference:}

Berndt, E., R. Hall, B. Hall, and J. Haumman, "Eatimation and Inference in Nonlinear Structural Modelg," Annals of Eeonomic and Social Measurement, 3 (1974), 653-55.

Bodurtha, James N., Jr., and Nelson C. Mark, "Testing the CAPM with Time-Varying Risks and Returns," Ohio State University, 1987.

Bollerslev, Tim, "A Conditionally Heteroskedastic Time Series Model for Security Prices and Rates of Return Data," Northwestern Univeraity, 1985.

Bolleralev, Tim, “Generalized Autoregresaive Conditional Heteroskedagticity," Journal of Econometrics, 31 (1986), 307-327.

Bollerslev, T., R.F. Engle, and J.M. Wooldridge, A Cepital Aset Pricing Model with TimeVarying Covariances," Journal of Political Economy, 98 (1988), 116-131.

Cox, W.M., "The Behevior of Treasury Securities; Monthly 1942-1984," Research Paper no. 8501, Dallas Federal Reserve Bank of Dallag, 1985.

Engel, Charles, and Anthony Rodrigues, "A Wald Test of International CAPM," Univeraity of Virginia, 1988.

Engel, Charles, and Anthony Rodrigues, "Testa of International CAPM with Time-Varying Covariances," forthcoming in Journal of Applied Econometrics, 1989.

Fama, Eugene F, and Kenneth R. French, "Permanent and Temporary Componente of Stock Prices," Journal of Political Economy, 96 (1988), 246-273.

Ferson, K.R., S. Kandel, and R.F. Stambaugh, "Tests of Asset Pricing with Time- Varying Expected Rikk Premiums and Market Betas," Journal of Finance, 42 (1987), 201-220.

Frankel, Jeffrey A., "In Search of the Exchange Risk Premium: A Six-Currency Test of MeanVariance Efficiency," Journal of International Money and Finence, 2 (1982).

Frankel, Jeffrey A., "Portfolio Shares as 'Beta-Breakers'," Journal of Portfolio Management, $11(19858), 18-23$.

Frankel, Jeffrey A., "Portfolio Crowding-out, Empirically Estimated," Quarterly Journal of Econamics, 100 (1985b), 1041-1065.

Frankel, Jeffrey A., and William Dickens, "Are Asset-Demand Functions Determined by CAPM?," University of California, Berkeley, 1984.

Frankel, Jeffrey A., and Charles Engel, "Do Asset Demand Functions Optimize Over the Mean and Variance of Real Returns? A Six Currency Test," Journal of International 
Economice, 17, December 1984.

French, Kenneth R. and Richard Roll, "Stock Retura Variances," Journal of Financial Economics, 17 (1986), 5-26.

Gibbong, Michsel R., and Jay Shanken, "Subperiod Aggregation and the Power of Multivariate Tests of Portfolio Elficiency," Journal of Financial Eeonomict, 19 (1987), 389-394.

Gibbons, M.R., S. Rose, and J. Shanken, "A Test of the Efficiency of a Given Portfolio," Stanford University, 1986.

Hansen, Lars P., and Scott Richard, "The Role of Conditioning Information in Deducing Testable Restrictions Implied by Dynamic Aseet Pricing Models," Econometrica, 55 (1987), 587-614.

Ibbotson Aseociates, Stocks, Bonda, Bills and Inflation: 1986 Yearbook, (Ibboteon Associates: Chicago) 1986.

MacKinlay, Craig, "On Multivariate Tests of the CAPM," Journal of Financial Economict, 18 (1987), 341-371.

Pindyck, R.S., "Risk, Inflation, and the Stock Market," American Economic Review, Vol. 74, pp. 335-51, June 1984 .

Poterba, J.M. and L.H. Summers, "The Persintence of Volatility and Stock Market Fluctuations," American Economic Review, Vol. 76, pp. 1142-1151, 1986.

Poterba, James M., and Lawrence Summers, "Mean Reversion in Stock Returns: Evidence and Implications," NBER Working Paper no. 1987.

Rayner, R.K., "Generalized Instrumental Variables Estimation under Rational Expectations on First and Second Moments," Ohio State University, 1986.

Roll, Richard, “A Critique of the Asset Pricing Theory's Tests; Part I: On Past and Potential Testability of the Theory," Journal of Financial Economics, 4 (1977), $129-76$.

Schwert, G. William, "Size and Stock Returns, and oth@r Empirical Regularities," Journal of Financial Economics, 12 (1983), 3-12.

Shanken, Jay, "Multivariate Tests of the Zero Beta CAPM," Journal of Finencial Economica, 14 (1985), 327-48.

Stambaugh, R., “On the Exclusion of Aasets from Tests of the Two Parameter Model: A Sensitivity Analysis," Journal of Financial Economics, 10 (1982), 237-268.

Wills, H., "Inferring Expectations," London School of Economics, 1982. 
Table I

Industry Portfolios and S,E.C. Codes

Industry

1. Mining

2. Food and Beverages.

3. Textile and Apparel

4. Paper Products

5. Chenical

6. Petroleum

7. Stone, Clay and Glass

8. Pтimary Metals

9. Fabricated Metals

10. Machinery

11. Appliances, Elec. Equip.

12. Transportation Equipment

13. Misc. Manufacturing

14. Railroads

15. Other Transportation

16. Utilities

1i. Department Stores

18. Cther Retail Trade

19. Bank., Fin, Real Estate

20. Miscellaneous
S.E.C. Codes

$$
\begin{aligned}
& 10,11,12,13,14 \\
& 20 \\
& 22,23 \\
& 26 \\
& 28 \\
& 29 \\
& 32 \\
& 33 \\
& 34 \\
& 35 \\
& 36 \\
& 37 \\
& 38,39 \\
& 40 \\
& 41,42,44,45,47 \\
& 49 \\
& 53 \\
& 50-52,54-59 \\
& 60-67 \\
& 1,4,15-17,21,24,25,27,30,31,46,48,70, \\
& 73,75,78,79,80,82,89,99
\end{aligned}
$$

11 Portfolios (Combirations of the 20 portfolios)

\section{Portfolio}

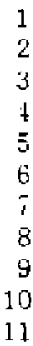

Industry Portfolios

$$
\begin{gathered}
1,20 \\
2,3,4 \\
5 \\
6 \\
7,8,9 \\
10 \\
11 \\
12-15 \\
16 \\
17,18 \\
19
\end{gathered}
$$

$\bar{i}$ Fortfolios lCombinations of the 20 portfollos:

Portfolio

1
2
3
1
5
1
7

lndustry. Portfolios

$$
\begin{gathered}
\text { 1. } 2,3,4,20 \\
5,5,8,9 \\
5
\end{gathered}
$$

10. 11

$12-15$

16

$1 \bar{i}-1 y$ 


\section{Table 2}

Estimated Coefficients from Unconstrained OLS Regressions

Dependent Variable: Excess rate of return on asset $j$ Independent Varjables: Shares of asset i in total portfolio

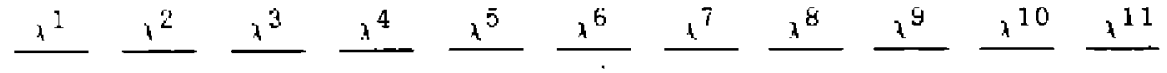

\section{Equation 1}

$\begin{array}{lllllllllll}-0.14 & 0.19 & 0.26 & -0.06 & -0.11 & 0.14 & -0.70 & 0.08 & 0.21 & -0.35 & 0.26\end{array}$ $(0.12)(0.82)(0.30)(0.26)(0.32)(0.25)(0.44)(0.22)(0.32)(0.25)(0.44)$

$$
\mathrm{R}^{2}=.023 \quad \text { Breusch-Godfrey statistic } 120 \text { lags } 1=42.79^{*}
$$

Equation 2

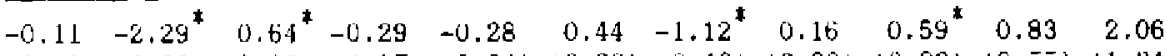
$(0.13)(0.86)(0.32)(0.27)(0.34)(0.26)(0.46)(0.23)(0.22)(0.57)(1.24)$

$$
\mathrm{F}^{2}=.050 \quad \text { Breusch-Godfrey statistic } 120 \text { lags } 1=23.38
$$

\section{Equation 3}

$\begin{array}{lllllllllll}-0.20 & -1.05 & 0.12 & -0.04 & -0.32 & 0.14 & -1.20^{*} & -0.02 & 0.46^{*} & 1.16 & 2.05\end{array}$ $(0.13)(0.89)(0.33)(0.28)(0.35)(0.27)(0.47)(0.24)(0.23)(0.59)(1.29)$

$$
\mathrm{R}^{2}=.047 \quad \text { Breusch-Godfrey statistic }(20 \text { lags })=16.99
$$

\section{Equation 4}

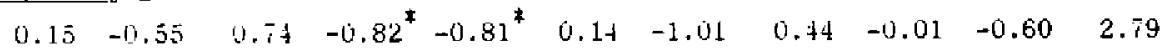
$(0.16)(1.09)(0.10)(0.34)(0.43)(0.33)(0.58)(0.29)(0.28)(0.72)(1.57)$

$$
R^{2}=.02 \bar{i} \quad \text { Breusch-Gadfrey statistic } 120 \text { lags } 1=21.74
$$

Equation 5

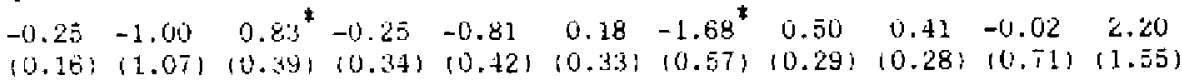

$$
R^{2}=.044 \quad \text { Breusch-Godfrey statistic }(20 \text { lags } 1=30.71
$$

Equation 6

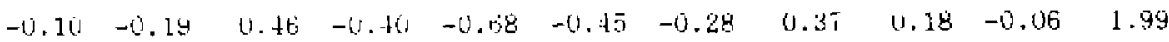

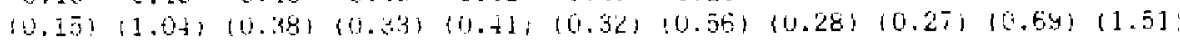

$$
H^{2}=\text {. Wh Breusch-rotfrey statistic } 120 \text { lags } 1=20.41
$$


$x^{1}+x^{2}+x^{3}+x^{4}+\frac{x^{5}}{2}+\frac{x^{8}}{2}+\frac{x^{9}}{2}+3^{11}$

\section{Equation 1}

$\begin{array}{lllllllllll}-0.17 & -2.72^{*} & 0.83^{*} & -0.26 & 0.71 & 0.44 & -2.15^{*} & 0.37 & 0.75 & 1.21 & 3.15\end{array}$ $(0.1)(1.13)(0.41)(0.36)(0.44)(0.35)(0.60)(0.30)(0.29)(0.75)(1.63)$

$$
\mathrm{R}^{2}=.066 \quad \text { Breusch-Godfrey statistic }(20 \text { lags } 1=17.38
$$

\section{Equation 8}

$\begin{array}{lllllllllll}-0.14 & -0.85 & 0.25 & -0.10 & -0.43 & 0.08 & -1.41^{*} & -0.04 & 0.62 & 0.94 & 1.80\end{array}$ $(0.14)(0.93)(0.34)(0.29)(0.36)(0.29)(0.49)(0.25)(0.24)(0.62)(1.34)$

$$
\mathrm{R}^{2}=.06 \overline{7} \quad \text { Breusch-Godfrey statistic }(20 \text { lags })=21.10
$$

\section{Equation 9}

$\begin{array}{ccccccccccc}-0.09 & -0.77 & 0.50 & -0.10 & -0.12 & 0.18 & -0.64 & -0.04 & 0.30 & 0.07 & 0.82 \\ (0.12) & 10.80) & (0.30) & (0.25) & (0.31) & 10.25) & (0.43) & (0.21) & (0.21) & (0.53) & (1.16)\end{array}$
$(0.12)(0.80)(0.30)(0.25)(0.31)(0.25)(0.43)(0.21)(0.21)(0.53)(1.16)$

$$
\mathrm{K}^{2}=.032 \quad \text { Breusch-Godfrey statistic }(20 \text { lags })=35.07^{*}
$$

Equation 10

$$
\begin{array}{ccccccccccc}
-0.11 & -0.38 & 0.20 & -0.10 & -0.27 & 0.01 & -0.56 & 0.06 & 0.41 & -0.02 & 1.05 \\
10.16) & (1.06) & 10.39) & (0.33) & (0.42) & (0.33) & 10.56) & (0.28, & (0.28) & (0.70) & (1.53)
\end{array}
$$

$$
\mathrm{R}^{2}=.027 \quad \text { Breusch-Godfrer statistic }(20 \text { lass })=44.68^{*}
$$

Equation 11

$\begin{array}{ccccccccccc}-0.04 & -0.25 & 0.13 & 0.19 & 0.09 & 0.24 & 0.13 & 0.19 & 0.54 & -0.20 & -1.31 \\ 10.14) & 10.95) & (0.35) & (0.30\} & (0.37) & 10.29) & (0.50) & (0.25) & 10.25 & 10.63) & (1.37)\end{array}$

$\mathrm{R}^{2}=.027 \quad$ Breusch-Godfrey statistic $\left(20\right.$ lags $1=42.42^{*}$

${ }^{*}=\operatorname{significant}$ at $95 \%$ kevel

(standard errors in parentheses ) 


\section{Table $\underline{3}$}

CAFM Estimation, constant 0,11 assets

$$
\begin{gathered}
r_{t+1}=\rho\left(P^{\prime} P\right)_{t}+e_{t+1} \\
\operatorname{Var}_{t}\left(\varepsilon_{t+1}\right)=P^{\prime} P
\end{gathered}
$$

*** Log Likelihood $=-8593.684711$

The estimate of the coefficient $\rho$ :

2.0319

$\{1.6130\}$

The estimate of the upper triangular matrix P:

$\begin{array}{lllllllllll}.0398 & .0322 & .0334 & .0385 & .0411 & .0346 & .0404 & .0331 & .0257 & .0316 & .0374\end{array}$

$(.0018)(.0021)(.0023)(.0028)(.0026)(.0026)(.0030)(.0025) 1.0022\}(.0029)(.0023\}$

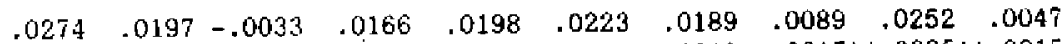

$$
\begin{aligned}
& (.0011)(.0015)(.0023)(.0019)(.0025)(.0022)(.0019)(.0017)(.0025)(.0015) \\
& \begin{array}{lllllllll}
.0204 & .0042 & .0044 & .0097 & .0097 & .0078 & -.0046 & .0015 & .0000
\end{array} \\
& (.0008)(.0024)(.0015)(.0019)(.0019)(.0014)(.0018)(.0018)(.0018) \\
& .0360-.0029-.0019-.0032-.0017 \quad .0018-.0073 \quad .0125 \\
& (.0014)(.0016)(.0021)(.0019)(.0015)(.0018)(.0019)(.0016\} \\
& \begin{array}{lllllll}
.0276 & .0058 & .0102 & .0090 & -.0046 & .0003 & .0051
\end{array} \\
& (.0011)(.0019\}(.0019)(.0013)(.0017)(.0017)(.0016) \\
& .0304 \quad .0068 \quad .0050-.0025 \quad .0021-.0009 \\
& (.0011)(.0016)+.0015)(.0017)(.0018)(.0014) \\
& \begin{array}{lllll}
.0272 & .0063 & .0000 & .0063 & .0020
\end{array} \\
& (.0011)(.0014)(.0017)(.0019)(.0017) \\
& \begin{array}{llll}
.0214 & .0020 \quad .0094 \quad .0027
\end{array} \\
& (.0010)(.0018)+.0018)(.0017) \\
& .027 \% \quad .0032 \quad .0050 \\
& (.0011)(.0017)(.0014) \\
& .0287 \quad .0006 \\
& (.0013) 1.0013
\end{aligned}
$$




\section{Table 4}

CAFM Estimation, Constant $\Omega, 7$ essets

$$
\begin{gathered}
\mathbf{r}_{\mathrm{t}+1}=\rho\left(\mathrm{P}^{\prime} \mathrm{P}\right)^{\gamma_{\mathrm{t}}}+\varepsilon_{\mathrm{t}+1} \\
\operatorname{Var}_{\mathrm{t}}\left(\varepsilon_{\mathrm{t}+1}\right)=\mathrm{P}^{\prime} \mathrm{P}
\end{gathered}
$$

\#\#* Log Likelihood $=\mathbf{- 5 5 5 8 . 5 6 1 2 4 7}$

The estimate of the coefficient $\rho$ :

2.02778

$(1.46639)$

The estimate of the upper triangular matrix $P$ :

$$
\begin{aligned}
& \begin{array}{lllllll}
.03842 & .03935 & .03711 & .04015 & .03640 & .02695 & .03782
\end{array} \\
& (.00150)(.00185)(.00246)(.00213)(.00206)(.00190)(.00197) \\
& \begin{array}{llllll}
.02075 & -.00471 & .01708 & .01571 & -.00389 & .00485
\end{array} \\
& (.00075)(.00225)(.00140)(.00149)(.00153)(.00123) \\
& \begin{array}{lllll}
.03757 & -.00296 & -.00242 & -.00033 & .00140
\end{array} \\
& (.00115)(.00143)(.00120)(.00166)(.00117) \\
& .02435 \quad .00762 \quad-.00136 \quad .00342 \\
& (.00092)(.00137)(.00156)(.00117) \\
& .02206 \quad .00269 \quad .00735 \\
& (.00087)(.00149)(.00108) \\
& .02801 \quad .00408 \\
& (.00103)(.00109) \\
& .02034 \\
& (.00075)
\end{aligned}
$$

istandard errors in parentheses I 


\section{Table 5}

CAPM Estimation, ARCH, 7 assets

$$
\begin{aligned}
r_{t+1} & =\rho \Omega_{t{ }_{t}+\varepsilon_{t+1}} \\
\operatorname{var}_{t}\left(\varepsilon_{t+1}\right) & =\Omega_{t}=P^{\prime} P+G \varepsilon_{t^{r} t^{\prime} G}
\end{aligned}
$$

*** Log Likelihood $=-5573.969787$

The estimate of the coefficient $\rho$ :

1.91212

$(1.47685)$

The estimate of the upper triangular matrix P:

$$
\begin{aligned}
& \begin{array}{llllllll}
.03714 & .03883 & .03364 & .04036 & .03738 & .02700 & .03700
\end{array} \\
& (.00152)(.00189)(.00274)(.00213)(.00204)(.00191)(.00200) \\
& \begin{array}{lllllll}
.02050 & -.00278 & .01648 & .01486 & -.00395 & .00494
\end{array} \\
& (.00077)(.00233)(.00150)(.00158)(.00160)(.00130) \\
& \begin{array}{ccccc}
.03541 & -.00285 & -.00127 & .00084 & .00082 \\
(.0016) & (.00157) & (.00124) & (.00182) & (.00128)
\end{array} \\
& \left.\begin{array}{cccc}
.02405 & .00687 & -.00140 & .00308 \\
(.00095) & (.00138) & (.00160) & (.00122
\end{array}\right) \\
& \begin{array}{ccc}
.02118 & .00253 & .00747 \\
.00096) & 1.00158 & 1.00109
\end{array} \\
& .02779 \quad .00391 \\
& (.00109)(.00112) \\
& .01971 \\
& 1,00082\}
\end{aligned}
$$

The estimates of the diagonal elements of $G$ :

$$
\begin{array}{ccccccc}
.19819 & .13305 & .31474 & .0626 i & -.03718 & .15481 & .17706 \\
(.0995 \% & (.04684) & 1.06162) & (.04517 & (.04355 & (.09849) & (.04668)
\end{array}
$$




\section{Tests of the model \\ $r_{1-1}+A_{1} \lambda_{t}+\varepsilon_{1-1} ; E_{1}\left[\varepsilon_{t-1} \varepsilon_{t+1},\right]=\Omega_{1-1}$}

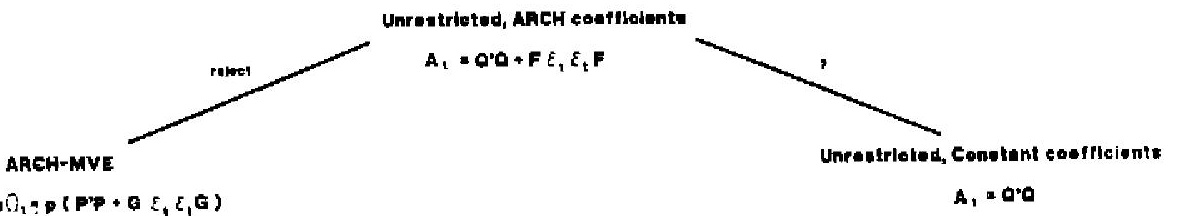

$A_{1}=P Q_{1} ! D\left(P P+G \varepsilon, c_{1} G\right)$

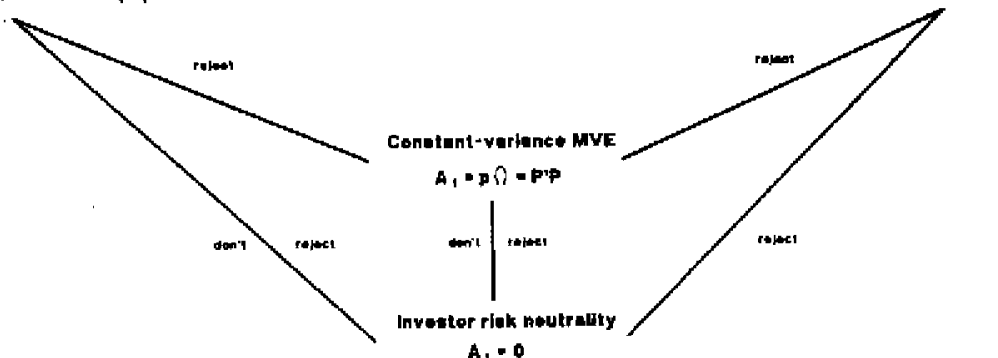

Figure 1 